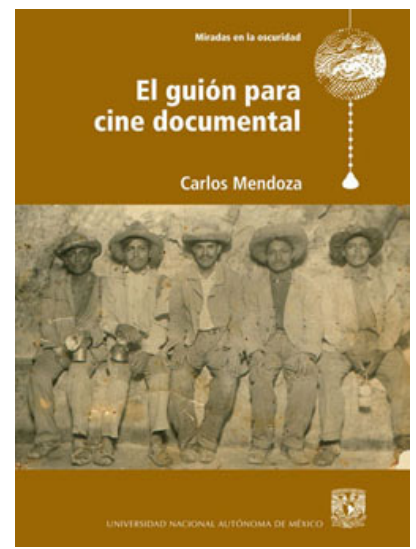

\title{
Carlos Mendoza
}

El GUIÓN PARA CINE DOCUMENTAL

Ciudad de México: Centro Universitario de Estudios

Cinematográficos

2010

Reseña de Guillermo Jarpa

Universidad de Chile

La práctica de la realización audiovisual denota una naturaleza más bien dinámica y flexible, sometida a los vaivenes de las transformaciones tecnológicas de su medio. Así también, su relación con el campo de lo económico y lo político evidencian que como objeto de estudio histórico y teórico, el cine se constituye como una articulación de orden complejo, donde las incertezas abundan en el ejercicio de establecer los límites epistémicos desde los cuales concebir una teoría sobre el cine. No obstante, el verdadero reto - al menos para un sector de la "academia" - consiste en como desarrollar, desde lo teórico, una concepción práctica que permita delimitar metodologías de realización, que auxilien en la formación de cineastas y audiovisualistas en general. Implícito en este programa subyace la pregunta por la consagración de estilos y escuelas, entendiendo que el modelo surge de "tradiciones" que se van transformando a través de la experimentación y extensión de sus métodos.

Al trasladar este foco problemático hacia el cine documental, pareciera que estas dificultades aumentan en grado, al sopesar el hecho de que el llamado género de "no-ficción" se realiza bajo modos de producción que gozan de mayor libertad. El cine documental al no encontrarse tan amarrado a las lógicas industriales del cine de ficción, permite la elaboración de metodologías más abiertas, que juegan y coquetean con sus propios límites abriendo el abanico de opciones estilísticas y discursivas. Bajo estas condiciones, ¿cómo se construye una teoría que devenga en práctica? 
En este escenario histórico y conceptual difuso aparece el libro "El guión para cine documental", de Carlos Mendoza, como un intento sincero por entregar un cierto orden a un paisaje cruzado por la diversificación y la constante búsqueda de nuevos modos de representación. El libro parte estipulando la dificultad con que se enfrenta cualquier escritor abocado a la tarea de sistematizar un saber relativo al quehacer audiovisual; y como esa dificultad se acentúa al enfrentar el género documental. Carlos Mendoza describe como el cine, en principio, situó su práctica en torno a la "representación de la realidad” tal como se enfrentaba a la cámara; por tanto se puede argumentar que el cine "nació documental", y su posterior consolidación como "narrativa de ficción” fue un largo proceso que involucró el ingreso de fáctores económicos y políticos que permitieran la consolidación de una industria. Antes de eso, era tan solo la curiosidad por captar la luz lo que movilizaba el ejercicio documental. ¿Cómo entonces establecer pautas para una práctica técnica que en si misma evade las sistematizaciones?

No obstante, como ya deja traslucir el título, el objetivo general del libro va más allá de la reflexión sobre el cine documental, sino que se plantea la pregunta por la naturaleza y la condición de uno de los elementos más volubles dentro de la realización documental: el guión. ¿A qué nos referimos con guión documenta? ¿Cómo lo han trabajado algunos de los representantes más relevantes del género? ¿Cuál es la función del guión documental? Estas preguntas, que no alcanzan a consagrar una respuesta, cimentan el desarrollo del libro, estructurado en dos partes: una primera parte dedicada a la contextualización del guión como disciplina, definida desde la experiencia de documentalistas y la teoría literaria y estética; y la segunda abocada a asuntos de índole práctica, que permitan sopesar el lugar que el guión puede tener en el proceso de realización documental, no obstante, como el mismo autor reitera una y otra vez a lo largo de las líneas, sin nunca pretender ser un manual o una caja de herramientas.

El texto inicia su desarrollo preguntándose por la relación que tiene la realización audiovisual con la academia, atendiendo a la dificultad inherente que involucra hacer de la práctica artística 
un "saber" reproducido institucionalmente. Desde ahí, el autor manifiesta que cualquier asomo de pregunta sobre la posibilidad de constituir definiciones (primer paso para el levantamiento de "saberes") resulta difícil, y que por tanto el libro se presenta mas bien como un intento por desentrañar algunos de los métodos de trabajo más importantes a lo largo de la historia del cine, desde las opiniones de los mismos autores. Este punto nos evidencia otra dificultad, esta vez de orden investigativo: para "desentrañar" los métodos de trabajo las fuentes son los testimonios de los realizadores - muchos de ellos teóricos del cine con sus respectivas bibliografias -, y no la evidencia empírica de su propia práctica audiovisual. Claramente esto dificulta establecer si lo que se nos entrega es tan solo la visión del realizador, o una puesta en práctica. El libro intenta resolver este escollo a partir de un ejercicio de generalización y sistematización conceptual, donde las posturas de Flaherty, Vertov, Rouch, Wiseman y otros, son contrastadas con el objetivo de poner en escena como han entendido la función del guión en el proceso de realización documental, con el objetivo de ser lo más amplio e imparcial posible.

Desde ahí, la argumentación se traslada hacia el campo teórico en un intento por evaluar los vínculos entre la literatura, el periodismo y el documental, comprendiendo que la pregunta por el guión se encuentra en un punto intermedio. El autor indica como el documental como género tiene fuertes lazos con el género literario histórico-periodístico, particularmente en la creación de la categoría de "trama argumentativa". Así, el documental en términos discursivos constituye una proposición política, en tanto se funda en "argumentos del mundo histórico", y desde ahí construye su trama. Las articulaciones que se fundan en este apartado permiten luego establecer las distintas modalidades del documental, de acuerdo al lugar que "lo retórico" tiene como construcción de trama, principalmente desde su relación con las estrategias del periodismo audiovisual. Para esto, Mendoza se apoya bastante en Bill Nichols y su canónico texto "La representación de la realidad", indicando la plena vigencia del autor estadounidense, como también la dificultad que entraña superar las concepciones más arraigadas de la teoría documental. Desde esto, la pregunta por "lo retórico" se desplaza al campo de la 
estética, a través de una breve - y quizás inecesaria, en el contexto global del libro - problematización del carácter de lo estético en el documental.

En la pregunta por lo dramático se encuentra un elemento de tensión interesante, que devela la dificultad que entraña pensar como entender el guión, en tanto proceso transcendental del cine de ficción, traducido al sistema de producción del cine documental. Si el libro pretende ser una introducción a la construcción argumentativa del documental, la pregunta por las modalidades dramáticas pertenecen mas bien al campo del montaje; el guión, en tanto "construcción de trama”, queda relegado tras su función primordial: planificar el rodaje. ¿Cómo entender, desde la planificación del rodaje, la pregunta por lo dramático - en tanto construcción de trama? Estas preguntas quedan irresueltas, aunque el libro es lo suficientemente recatado como para admitir que esas búsquedas son parte de una investigación más profunda. En ese sentido, el libro adquiere mayor sentido en la segunda parte, al trabajar aspectos prácticos que, en tanto pautas y consejos, pueden ser de utilidad al realizador documental. Mas allá, están las preguntas. 